\title{
Astrocyte Calcium Signaling: From Observations to Functions and the Challenges Therein
}

\author{
Baljit S. Khakh ${ }^{1}$ and Ken D. McCarthy ${ }^{2}$ \\ ${ }^{1}$ Departments of Physiology and Neurobiology, David Geffen School of Medicine, University of California, \\ Los Angeles, Los Angeles, California 90095 \\ ${ }^{2}$ Department of Pharmacology, University of North Carolina at Chapel Hill, Chapel Hill, North Carolina \\ 27599-7365 \\ Correspondence: bkhakh@mednet.ucla.edu; kdmc@med.unc.edu
}

\begin{abstract}
We provide an overview of recent progress on the study of astrocyte intracellular $\mathrm{Ca}^{2+}$ signaling. We consider the methods that have been used to monitor astrocyte $\mathrm{Ca}^{2+}$ signals, the various types of $\mathrm{Ca}^{2+}$ signals that have been discovered (waves, microdomains, and intrinsic fluctuations), the approaches used to broadly trigger and block $\mathrm{Ca}^{2+}$ signals, and, where possible, the proposed and demonstrated physiological roles for astrocyte $\mathrm{Ca}^{2+}$ signals within neuronal microcircuits. Although important progress has been made, we suggest that further detailed work is needed to explore the biophysics and molecular mechanisms of $\mathrm{Ca}^{2+}$ signaling within entire astrocytes, including their fine distal extensions, such as processes that interact spatially with neurons and blood vessels. Improved methods are also needed to mimic and block molecularly defined types of $\mathrm{Ca}^{2+}$ signals within genetically specified populations of astrocytes. Moreover, it will be essential to study astrocyte $\mathrm{Ca}^{2+}$ activity in vivo to distinguish between pharmacological and physiological activity, and to study $\mathrm{Ca}^{2+}$ activity in situ to rigorously explore mechanisms. Once methods to reliably measure, mimic, and block specific astrocyte $\mathrm{Ca}^{2+}$ signals with high temporal and spatial precision are available, researchers will be able to carefully explore the correlative and causative roles that $\mathrm{Ca}^{2+}$ signals may play in the functions of astrocytes, blood vessels, neurons, and microcircuits in the healthy and diseased brain.
\end{abstract}

Calcium ions are a ubiquitous inorganic signaling species that play myriad fundamental roles in nearly all aspects of biology in diverse species from most phyla (Clapham 2007). From the fertilization of an egg to the death of a cell, from muscle contraction to neurite extension, and from the release of neurotransmitters/hormones to synaptic plasticity, temporally and spatially restricted $\mathrm{Ca}^{2+}$ fluxes are essential. Not surprisingly, clarifying the biophysical and physiological mechanisms underlying the regulation of $\mathrm{Ca}^{2+}$ has been central to many advances in biology. Recalling the way in which electrophysiology allowed neuroscientists to explore neuronal activity (Scanziani and Häusser 2009), the development of tools for monitoring $\mathrm{Ca}^{2+}$ concentrations and fluxes has enabled researchers to explore $\mathrm{Ca}^{2+}$ signaling in nonexcitable

Editors: Ben A. Barres, Marc R. Freeman, and Beth Stevens

Additional Perspectives on Glia available at www.cshperspectives.org

Copyright (C) 2015 Cold Spring Harbor Laboratory Press; all rights reserved; doi: 10.1101/cshperspect.a020404

Cite this article as Cold Spring Harb Perspect Biol 2015;7:a020404 
cells including glia (Tsien 1988, 1989). One of the first demonstrations of dynamic $\mathrm{Ca}^{2+}$ fluctuations and regulation in astroglia came from the laboratory of Stephen Smith (Cornell-Bell et al. 1990). Using hippocampal explant cultures and organic $\mathrm{Ca}^{2+}$ indicator dyes, these and other investigators beautifully demonstrated that astroglia exhibited "spontaneous" calcium elevations that propagated in complicated patterns throughout cells as well as developed into $\mathrm{Ca}^{2+}$ waves that propagated over long distances and involved many individual cells (Cornell-Bell et al. 1990; Charles et al. 1991; Dani et al. 1992). Further, these investigators found that the activation of neurotransmitter receptors increased $\mathrm{Ca}^{2+}$ signaling within astroglial cells. These main observations are preserved in astrocytes in situ and in vivo in awake mice. Consequently, with respect to astrocyte signaling, focus over the past two decades has been on an analysis of the mechanisms and roles of astrocyte $\mathrm{Ca}^{2+}$ fluxes in situ and, more recently, in vivo. In many ways, Stephen Smith provided the basis and rationale for these studies in the early 1990s with two thought-provoking essays that are apt even today (Smith 1992, 1994).

\section{APPROACHES TO MONITOR $\mathrm{Ca}^{2+}$ SIGNALS \\ Organic $\mathrm{Ca}^{2+}$ Indicator Dyes}

Our understanding and ability to formulate hypotheses on the roles of astrocyte $\mathrm{Ca}^{2+}$ relies heavily on our ability to faithfully measure the underlying $\mathrm{Ca}^{2+}$ signals in physiologically relevant astrocyte compartments (Fig. 1). The methods used to image astrocyte $\mathrm{Ca}^{2+}$ signals have recently been reviewed (Tong et al. 2012; Li et al. 2013). It is important to remember that, by definition, all available methods have the potential to buffer $\mathrm{Ca}^{2+}$ because they all rely on $\mathrm{Ca}^{2+}$ binding. Hence, $\mathrm{Ca}^{2+}$ indicators should be used at concentrations that do not exceed the buffering capacity of the cells being studied (Tsien 1988; Neher 2000). In most cases, this means concentrations in the micromolar range when measuring bulk cytosolic $\mathrm{Ca}^{2+}$ signals with organic indicator dyes, such as Fluo-4 and Fura, but this will depend on the specifics of the experiment at hand and the dyes being used. De- tailed information on the biophysical aspects of astrocyte $\mathrm{Ca}^{2+}$ buffering does not exist and precise guidelines are not possible at present.

Starting from the initial studies of Smith and colleagues, organic $\mathrm{Ca}^{2+}$ indicator dyes have been vital in the exploration of astrocyte physiology and the dynamics of $\mathrm{Ca}^{2+}$ signals. These indicators are available in a range of $\mathrm{Ca}^{2+}$ affinities, binding/unbinding kinetics and spectral properties. Organic $\mathrm{Ca}^{2+}$ indicator dyes have been extensively used and the data obtained with them has significantly advanced our understanding of astrocyte-neuronal interactions.

One of the most common methods to study astrocytes is bulk loading of membrane-permeable organic $\mathrm{Ca}^{2+}$ indicator dyes. The method is extensively used because of its ease and relative specificity for astrocytes, which can be confirmed using another astrocyte-specific vital dye, sulforhodamine 101 (Nimmerjahn et al. 2004). Although this method remains powerful for studying astrocyte $\mathrm{Ca}^{2+}$ signals, it does have limitations and its utility needs to be considered depending on the question at hand. First, it has been known for over two decades that bulk loading is problematic in adult tissue, although it works reproducibly in brain slices from young rodents (Yuste and Katz 1991; Haustein et al. 2014). Second, bulk loading fails to report on finer astrocyte structures, such as branches and branchlets, leaving $\sim 90 \%$ of the cell unsampled (Reeves et al. 2011). This is an important limitation because astrocytes interact with neurons via their fine distal extensions (Fig. 1). Therefore, it is likely that the most important compartments of astrocyte-neuron interactions cannot be effectively studied using bulk loading methods. The disconnect between where astrocyte $\mathrm{Ca}^{2+}$ signals have been measured (i.e., largely in the soma) and where they underlie physiological responses (likely in finer processes) has contributed to an incomplete picture of the role of astrocyte $\mathrm{Ca}^{2+}$ in physiology, as recently proposed (Reeves et al. 2011; Tong et al. 2012; Shigetomi et al. 2013a). Broadly, this conceptual problem may be analogous to trying to accurately measure events from dendritic spines and nerve terminals using somatic electrophysiological recordings from neurons. In both of these 


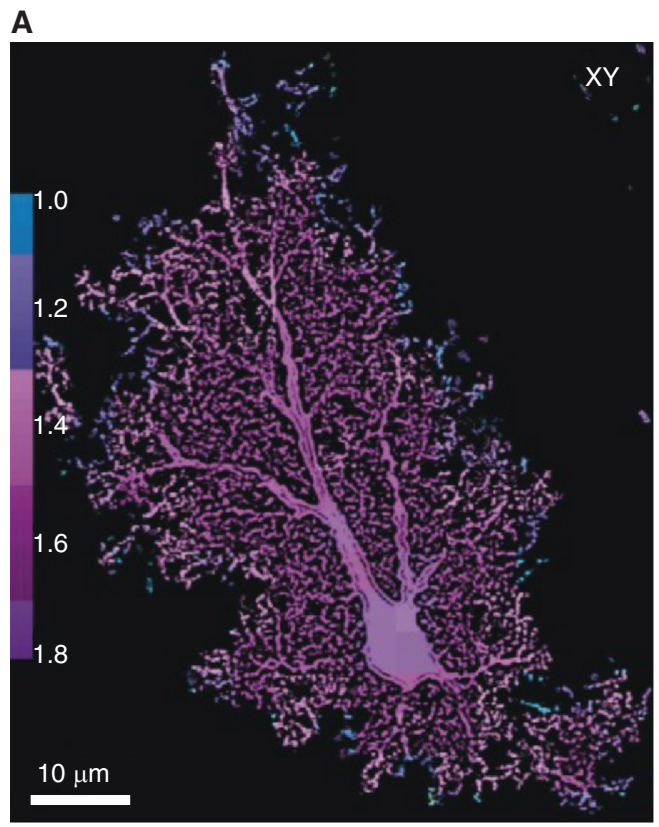

B

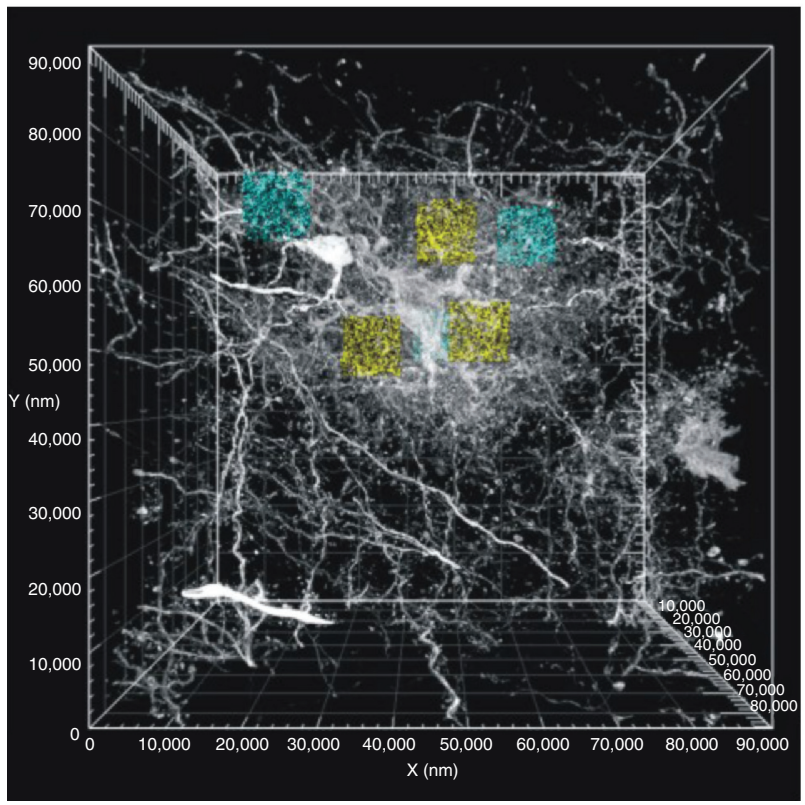

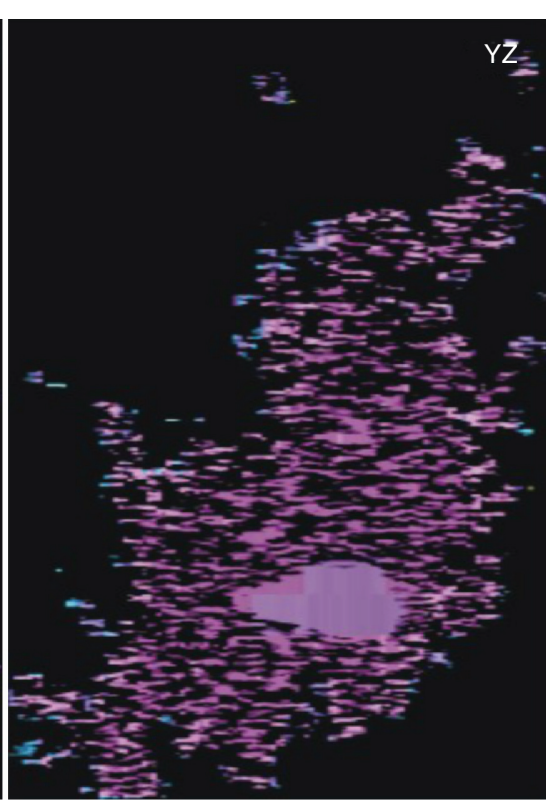

C

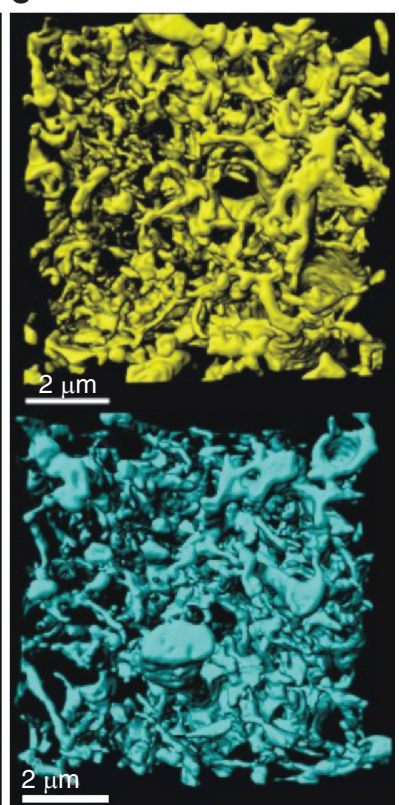

Figure 1. Electron and light microscopy analysis of astrocyte processes. (A) Orthogonal slices through a confocal volume of a dye-filled astrocyte. Box counting fractal analysis was performed to determine the local $D_{F}$ across the astrocyte territory. The vast majority of the territory has a $D_{F}$ of $\sim 1.7$, extending from the soma to the periphery, as shown by the colored scale bar. This implies that astrocytes are approximately equally complex throughout their territories. $(B)$ Electron microscopic volume of an entire Golgi-impregnated astrocyte. Three perisomatic (yellow) and three peripheral (cyan; one of them is behind a yellow one in the view shown) subvolumes $\left(\sim 680 \mu \mathrm{m}^{3}\right.$ each) have been extracted to determine surface area and volume of astrocyte branchlets. $(C)$ Close-up views of astrocyte processes in perisomatic and peripheral subvolumes demonstrating dense network of fine branchlets in both regions. These analyses reveal that astrocytes have thousands of branches that are the primary sites for interactions with neurons. However, as discussed in the text, $\mathrm{Ca}^{2+}$ signals have not been studied in the fine structures. (From Shigetomi et al. 2013a; reproduced, with permission, from the authors as well as by the Creative Commons license for reuse in the public domain.) 
cases, direct exploration of dendritic signaling and nerve terminals necessitated the development of methods to record directly from dendrites (Stuart et al. 1993) and presynaptic nerve terminals (Bischofberger et al. 2006).

Patch pipette-mediated loading of membrane-impermeable organic $\mathrm{Ca}^{2+}$ indicator dyes has also been used to measure astrocyte $\mathrm{Ca}^{2+}$ signals based on pioneering work (Nett et al. 2002). This method has a number of advantages, including the fact that an identified astrocyte is loaded with a known concentration of dye, and the loading is often more complete than with bulk loading, permitting evaluation of the major astrocyte processes (Agulhon et al. 2010; Di Castro et al. 2011; Panatier et al. 2011). However, patch-mediated dialysis of astrocytes with $\mathrm{Ca}^{2+}$ indicator dyes introduces several problems that need to be carefully considered depending on the specifics of the experiment at hand. First, patch-mediated dialysis of $\mathrm{Ca}^{2+}$ indicator dyes does not provide information on fine astrocyte processes. Second, to obtain complete loading of astrocytes, quite high amounts of $\mathrm{Ca}^{2+}$ indicator dye are often used (up to $0.5 \mathrm{~mm}$ ). The use of high concentrations means that the dye will alter $\mathrm{Ca}^{2+}$ signals and $\mathrm{Ca}^{2+}$-dependent processes within astrocytes (Tsien 1988; Neher 2000). Third, the act of patching cells not only introduces the dye into them, but also washes out intracellular components from within. This procedure also has the potential to alter cell properties (Rand et al. 1994). Nonetheless, when used judiciously, patch-mediated dialysis remains an important method to explore astrocyte $\mathrm{Ca}^{2+}$ signals.

\section{Genetically Encoded $\mathrm{Ca}^{2+}$ Indicators (GECls)}

Building on work with fluorescence resonance energy transfer based $\mathrm{Ca}^{2+}$ indicators expressed in astrocytes (Atkin et al. 2009; Russell 2011), our laboratory (Khakh laboratory) recently sought to measure $\mathrm{Ca}^{2+}$ signals in astrocytes using single-wavelength genetically encoded $\mathrm{Ca}^{2+}$ indicators (GECIs) based on circularly permuted green fluorescent protein (Hires et al. 2008; Tian et al. 2009). We focused on using a membrane-targeted GECI and a cytosolic form (Fig.
2). The rational for using a membrane-targeted GECI and a cytosolic one was based on the fact that rapid switching between evanescent and wide-field microscopy revealed that many cytosolic $\mathrm{Ca}^{2+}$ signals failed to elevate $\mathrm{Ca}^{2+}$ near the plasma membrane of astroglia (Shigetomi et al. 2010b). Additionally, some $\mathrm{Ca}^{2+}$ signals happened only in near membrane regions (Shigetomi et al. 2010b). Finally, the sites of interaction between neurons and astrocytes in vivo are likely to be in the extensive small processes that have high surface areas and low internal volumes (Fig. 1), implying that a membrane-targeted GECI may be better than a cytosolic one to image $\mathrm{Ca}^{2+}$ signals within them (Shigetomi et al. 2010b). Based on these considerations, we first generated Lck-GCaMP2, and then improved the GECI iteratively in terms of signal-to-noise, expression level, and kinetics to generate LckGCaMP3 and Lck-GCaMP5G (Shigetomi et al. 2010a, 2011; Akerboom et al. 2012). "Lck" refers to a 26-amino-acid peptide that has been shown to be a strong membrane tether (Zlatkine et al. 1997; Benediktsson et al. 2005) and "GCaMP" refers to widely used single wavelength GECIs (Hires et al. 2008; Tian et al. 2009). Lck-GCaMP3 and $5 \mathrm{G}$ share many benefits of Lck-GCaMP2, but display better signal-to-noise ratios and expression levels. Most recently, we made LckGCaMP6 and tested it (along with cytosolic GCaMP6) in relation to GCaMP3 (Haustein et al. 2014). These are the current GECIs of choice, with GCaMP6 displaying kinetics as fast as an organic $\mathrm{Ca}^{2+}$ indicator dye (Chen et al. 2013). Together, the membrane-targeted and cytosolic GECIs represent useful tools to measure nearmembrane and cytosolic $\mathrm{Ca}^{2+}$ signals in adult tissue (Shigetomi et al. 2013a,b). As mentioned earlier, GECIs have the potential to buffer $\mathrm{Ca}^{2+}$, but this has not proved problematic in several studies of neurons and astrocytes, perhaps because they are expressed in low micromolar amounts using the methods that have been used to date, such as adeno-associated viruses and knockin mice (Tian et al. 2009; Zariwala et al. 2012; Chen et al. 2013; Shigetomi et al. 2013a,b). The biggest challenge in using GECIs is the need for specialized methods to deliver the genes to astrocytes, necessitating the need to gen- 
A

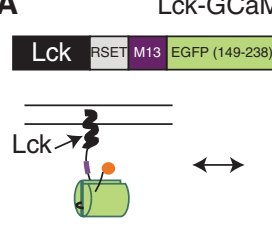

"Dim" GCaMP3
"Bright" GCaMP3

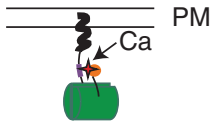

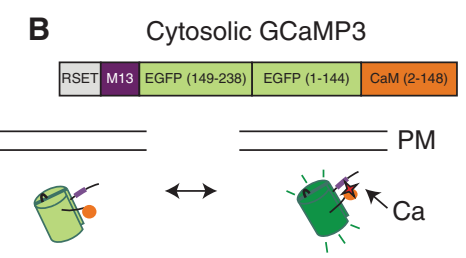

"Dim" GCaMP3
"Bright” GCaMP3
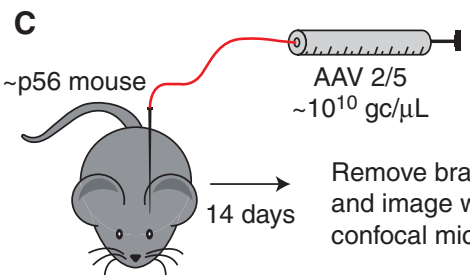

Remove brain, slice, and image with confocal microscopy

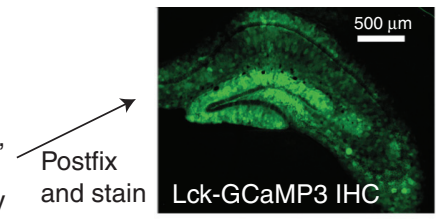

D
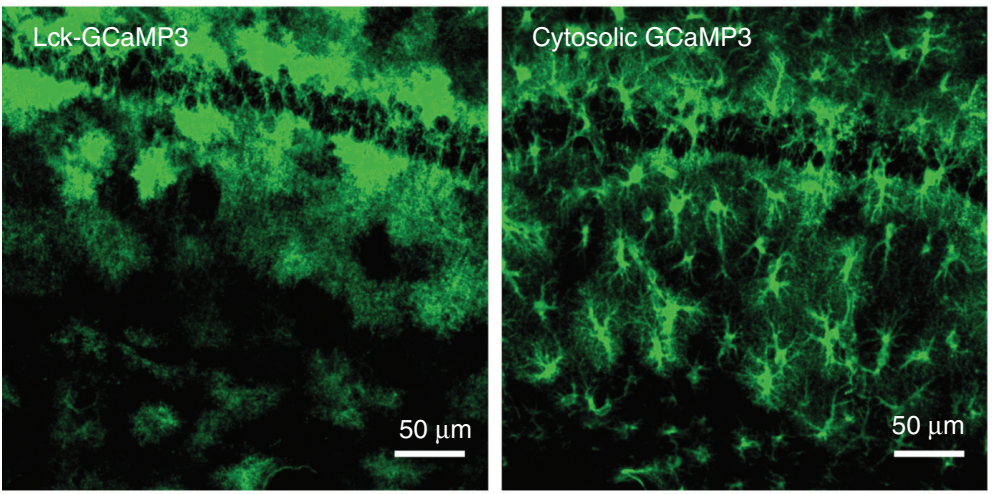

E

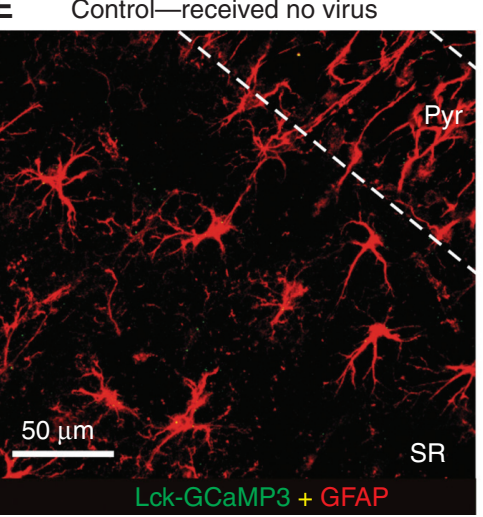

AAV 2/5 for Lck-GCaMP3

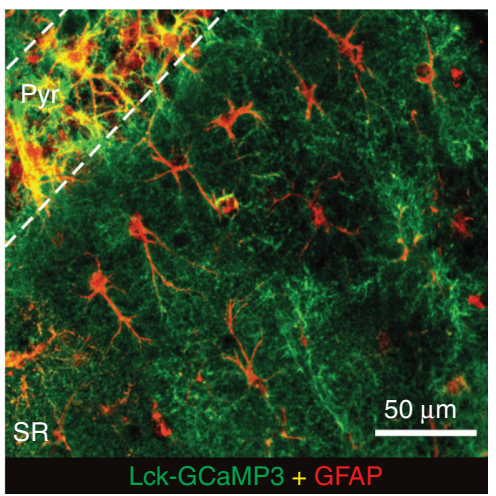

Figure 2. Expression of cytosolic GCaMP3 and Lck-GCaMP3 throughout astrocytes. $(A, B)$ Cartoons of differences between cytosolic and membrane-targeted GECIs. $(C)$ Schematic illustrates the protocol for AAV 2/5 microinjections into the hippocampus. The right-hand image shows the expression of Lck-GCaMP3 throughout the hippocampus, and $D$ shows expression within the stratum radiatum region for Lck-GCaMP3 and cytoGCaMP3. (E) Representative images showing GFAP and GCaMP3 staining for the stratum radiatum region from control mice that received no AAVs and those that received AAV2/5 Lck-GCaMP3. The image is a zoomedout view. AAV, adeno-associated virus; gc, genome copy; PM, plasma membrane. (From Shigetomi et al. 2013a; reproduced, with permission, from the authors as well as by the Creative Commons license for reuse under the public domain.) 
erate and test viruses (Fig. 2), or transgenic approaches, which can be time consuming and expensive. However, both methods have been used with success and with little evidence of deleterious effects on astrocytes (Zariwala et al. 2012; Shigetomi et al. 2013a). Cre-dependent knockin mice and adeno-associated viruses (AAVs) capable of delivering GECIs to astrocytes are widely available from Jackson Laboratories and the Penn Vector Core (University of Pennsylvania) (Zariwala et al. 2012; Shigetomi et al. 2013b). Very recently, our work with GECIs in situ following in vivo expression with viruses (Fig. 2) has been extended to studies in vivo with Credependent GCaMP3 knockin mice in which the approach worked and revealed robust $\mathrm{Ca}^{2+}$ signals within large parts of astrocyte territories (Paukert et al. 2014).

\section{TYPES OF ASTROCYTE CALCIUM SIGNALS}

Intrinsic Calcium Fluctuations and Calcium Waves

Astrocytes, like many cell types, show intrinsic $\mathrm{Ca}^{2+}$ fluctuations that occur in the absence of external signals (Nett et al. 2002). Aside from the initiating events, the mechanisms underlying intrinsic $\mathrm{Ca}^{2+}$ fluctuations and intracellular $\mathrm{Ca}^{2+}$ waves have been studied extensively and are reasonably well understood (Berridge et al. 2003). At distinct sites within cells, there are bursts of $\mathrm{Ca}^{2+}$ release from the $\mathrm{IP}_{3}$ receptors/ channels ( $\left.\mathrm{IP}_{3} \mathrm{Rs}\right)$ located in the membrane of the endoplasmic reticulum (ER). Events that trigger these localized $\mathrm{Ca}^{2+}$ increases may include (1) a high density of Gq G-protein coupled receptors (GPCRs) whose intrinsic activity generates a sufficient level of $\mathrm{IP}_{3}$ to activate nearby $\mathrm{IP}_{3}$ receptors, (2) focal points of elevated $\mathrm{Ca}^{2+}$, which acts as a coagonist at $\mathrm{IP}_{3} \mathrm{Rs}$, or (3) the $\mathrm{Ca}^{2+}$ "load" of a restricted region within the ER. Intracellular $\mathrm{Ca}^{2+}$ waves result from the diffusion of $\mathrm{Ca}^{2+}$ to neighboring $\mathrm{IP}_{3} \mathrm{Rs}$ where, in the presence of $\mathrm{IP}_{3}, \mathrm{Ca}^{2+}$ can induce $\mathrm{Ca}^{2+}$-induced $\mathrm{Ca}^{2+}$ release (CICR). Intracellular $\mathrm{Ca}^{2+}$ waves follow a specific spatial path within cells that is dependent on the proximity of $\mathrm{ER} \mathrm{IP}_{3} \mathrm{Rs}$; if the nearest $\mathrm{IP}_{3} \mathrm{R}$ is too distant, $\mathrm{Ca}^{2+}$ is buffered to basal levels and the intracellular $\mathrm{Ca}^{2+}$ wave ter- minates. Therefore, it is the spatial distribution of $\mathrm{IP}_{3} \mathrm{Rs}$ that provides a path for intracellular $\mathrm{Ca}^{2+}$ waves. Increasing concentrations of GqGPCR agonists leads to increases in the frequency of $\mathrm{Ca}^{2+}$ fluctuations and distance traveled by intracellular $\mathrm{Ca}^{2+}$ waves without a marked effect on the amplitude of $\mathrm{Ca}^{2+}$ responses (Shao and McCarthy 1993); the mechanism(s) underlying frequency changes has not been resolved. As the concentration of the Gq-GPCR agonist increases, it is possible to obtain a sustained increase in $\mathrm{Ca}^{2+}$ that is caused by the opening of store-operated $\mathrm{Ca}^{2+}$ channels and entrance of extracellular $\mathrm{Ca}^{2+}$; there is little evidence that this occurs in astrocytes under physiological conditions. Intrinsic $\mathrm{Ca}^{2+}$ fluctuations and intracellular $\mathrm{Ca}^{2+}$ waves are observed in astroglia in culture, as well as in astrocytes in acutely isolated brain slices (Fatatis and Russell 1992; Nett et al. 2002). The role(s) of intrinsic $\mathrm{Ca}^{2+}$ fluctuations and associated short-range $\mathrm{Ca}^{2+}$ waves has not been resolved. Given that these events occur independently of neuronal activity (Shao and McCarthy 1993; Nett et al. 2002) and are generally not synchronized with adjacent astrocytes, it is possible that there are inherent processes within astrocyte microdomains that affect local neural activity. That is, different regions of a given astrocyte may differentially affect local signaling events. For example, although not known, it is possible that individual microdomains within an astrocyte are independently regulating the local level of extracellular $\mathrm{K}^{+}$, glutamate, $\gamma$-aminobutyric acid (GABA), adenosine, nitric oxide (NO), or prostaglandins, as well as perhaps influencing dendritic spine formation through the release of trophic factors.

\section{Transmembrane $\mathrm{Ca}^{2+}$ Signals and "Spotty" Microdomains}

The vast majority of studies in this area have focused on store-mediated $\mathrm{Ca}^{2+}$ signals in astrocytes (see preceding sections), but there is a growing literature on ligand-gated cation channels in astrocytes. For example, activation of P2X and N-methyl-D-aspartic acid (NMDA) receptors leads to $\mathrm{Ca}^{2+}$ elevations in cortical astrocytes (recently reviewed in Pankratov and 
Lalo 2013). The extent to which these ion channels contribute either to basal $\mathrm{Ca}^{2+}$ levels or to intrinsic $\mathrm{Ca}^{2+}$ fluctuations is incompletely explored, but pharmacological experiments suggest they can be activated during synaptic neurotransmitter release (Palygin et al. 2010). For the remainder of this section, we focus on recent work that shows that astrocyte TRPA1 channels contribute to basal $\mathrm{Ca}^{2+}$ levels and to a fraction of intrinsic fluctuations in the CA1 region of the hippocampus.

Using membrane-targeted GECIs, one of us (Khakh laboratory) discovered a transmembrane $\mathrm{Ca}^{2+}$ flux pathway mediated by TRPA1 channels in astrocytes (Shigetomi et al. 2010b, 2011). These channels mediate spotty $\mathrm{Ca}^{2+}$ microdomains that are independent of those mediated by IP3R-dependent $\mathrm{Ca}^{2+}$ release from ER stores, but nonetheless contribute to basal $\mathrm{Ca}^{2+}$ levels within astrocytes. TRPA1-mediated microdomains have been observed in cell culture and in situ (Shigetomi et al. 2010a, 2011, 2013a,b). The discovery of TRPA1 channels in astrocytes and their contribution to near membrane and basal $\mathrm{Ca}^{2+}$ signals adds to the diversity of $\mathrm{Ca}^{2+}$ signals in astrocytes. Much more work is needed to explore other candidate mechanisms that may also lead to the elevation of $\mathrm{Ca}^{2+}$ levels or contribute to basal $\mathrm{Ca}^{2+}$ levels, including ligand-gated ion channels (Pankratov and Lalo 2013), TRPC channels (Malarkey et al. 2008), and several classes of transporters (Nedergaard et al. 2010). To a large extent, these areas have not been fully explored so far. Work on Drosophila melanogaster may be portentous (Melom and Littleton 2013).

An important aspect of TRPA1-mediated spotty $\mathrm{Ca}^{2+}$ signals within astrocytes was that TRPA1 blockades reduced basal cytosolic $\mathrm{Ca}^{2+}$ levels (Shigetomi et al. 2011). It remains feasible (but unproven) that the spotty $\mathrm{Ca}^{2+}$ signals may themselves regulate astrocyte $\mathrm{Ca}^{2+}$ levels locally within microdomains, but the available data suggest that they contribute to bulk intracellular basal $\mathrm{Ca}^{2+}$ levels. An additional feature of the TRPA1-mediated spotty $\mathrm{Ca}^{2+}$ signals that set them apart from other astrocyte $\mathrm{Ca}^{2+}$ signals is that they seem not to be regulated by, or require, neuronal activity or GPCR activation (Shigetomi et al. 2011), making it unlikely that TRPA 1 channels contribute to active neuron-to-astrocyte communication. Based on the available data, two functions have been discovered for astrocyte TRPA1 channels using TRPA1 knockout mice and selective TRPA1 antagonists. The first are the indirect actions on inhibitory GABAergic synaptic transmission onto interneurons located in the stratum radiatum region of the hippocampus (Shigetomi et al. 2011). The mechanism involves TRPA1-mediated contributions to basal $\mathrm{Ca}^{2+}$ levels, which, in turn, regulate astrocyte GABA transporters of the GAT-3 subtype (Shigetomi et al. 2011). The second mechanism also involves TRPA1-mediated basal astrocyte $\mathrm{Ca}^{2+}$ levels, which are permissive for the release of D-serine (Shigetomi et al. 2013a). D-serine is thought to set the tone for NMDA-receptor-dependent long-term synaptic plasticity of excitatory synapses onto CA1 pyramidal neurons in the hippocampus (Shigetomi et al. 2013a). In both of these cases, astrocyte basal $\mathrm{Ca}^{2+}$ signals seem to indirectly contribute to neuronal function (via GABA transport and D-serine levels). We found no evidence to suggest that elevated $\mathrm{Ca}^{2+}$ signals mediated by TRPA1 channels affected either inhibitory synaptic transmission or synaptic plasticity (Shigetomi et al. 2011, $2013 \mathrm{~b}$ ). The potential contribution(s) of basal $\mathrm{Ca}^{2+}$ levels to other aspects of astrocyte physiology remains incompletely explored. In recent studies, we found that TRPAl channels did not contribute to $\mathrm{Ca}^{2+}$ signals within astrocytes located in the stratum lucidum within the CA3 region of the hippocampus (Haustein et al. 2014). We interpret this to provide the first functional evidence for astrocyte heterogeneity even within subfields of the hippocampus.

Increases in Astrocytic Calcium Mediated by Neurons In Situ and In Vivo

Strong evidence shows that astrocytes in situ and in vivo respond to neuronal activity with increases in $\mathrm{Ca}^{2+}$. This was initially observed in acutely isolated hippocampal slices where electrical stimulation of the Schaffer collateral pathway led to increases in astrocytic $\mathrm{Ca}^{2+}$ via the activation of Gq-coupled GPCRs (Porter and 
McCarthy 1996). Subsequent studies from a large number of laboratories indicate that neuronal activation in situ leads to increases in astrocytic $\mathrm{Ca}^{2+}$ (Carmignoto and Haydon 2012). Although this was an important observation, the question remained whether physiological stimuli lead to increases in astrocytic $\mathrm{Ca}^{2+}$. Over the past several years, evolving technology has enabled investigators to monitor astrocyte $\mathrm{Ca}^{2+}$ responses to sensory stimulation in vivo using cranial windows and to relate this to neuronal activity in a correlative manner. Findings from these studies show that astrocytes in vivo respond to sensory input with increases in $\mathrm{Ca}^{2+}$ (Wang et al. 2006; Nimmerjahn et al. 2009). Interestingly, the form of astrocyte $\mathrm{Ca}^{2+}$ responses to sensory stimulation varies markedly among brain regions and experimental conditions. For example, most cortical astrocytes respond to whisker stimulation with $\mathrm{Ca}^{2+}$ responses restricted to their processes with little evidence of widespread $\mathrm{Ca}^{2+}$ waves (Wang et al. 2006), but later studies in awake mice with the startle response show widespread wave-like $\mathrm{Ca}^{2+}$ signals among astrocytes (Ding et al. 2013). In contrast, Bergmann glia can show large-scale $\mathrm{Ca}^{2+}$ waves involving hundreds of Bergmann glia during motor activity (Nimmerjahn et al. 2009). Sensory-and motor-driven astrocyte responses appear to primarily arise from glutamatergic input (Wang et al. 2006; Nimmerjahn et al. 2009), but startle responses are mediated by noradrenaline from the locus coeruleus (LC) (Ding et al. 2013). This is particularly interesting given the role of the LC in modulation of cortical activity (Aston-Jones and Cohen 2005; O'Donnell et al. 2012). In accord, recent studies suggest that astrocytes respond to local cortical activity when they are stimulated by norepinephrine release from LC projections (Paukert et al. 2014). It is likely that astrocyte responses to input arriving directly from the sensory system and those arriving from internal regulatory systems, such as the LC, play distinct roles in modulating/supporting neuronal activity, but this remains to be shown. Another interesting finding is that astrocytes in the visual cortex of ferrets show orientation and spatial frequency tuning, as measured by their $\mathrm{Ca}^{2+}$ responses, similar to neurons
(Schummers et al. 2008). Similar findings have not been observed in mice (McCarthy laboratory; KD McCarthy, unpubl.). A major difference in the visual cortex of ferrets and mice is that ferrets show the columnar visual columns typical of higher mammals, whereas mice do not. These findings suggest, not surprisingly, that caution is needed when extrapolating findings among different rodents to higher-level organisms, such as primates. Overall, it is apparent that astrocytes in vivo respond in a correlated manner during neuronal activity with increases in $\mathrm{Ca}^{2+}$, and that the spatial and temporal characteristics of astrocyte $\mathrm{Ca}^{2+}$ responses vary dependent on the level and type of neural activity as well as with brain vigilance state (awake/anesthetized).

\section{Intercellular Calcium Waves}

One of the first observations made in this area was that cultured astroglia show intercellular $\mathrm{Ca}^{2+}$ waves that propagate long distances and can involve hundreds of cells (Cornell-Bell et al. 1990). This led to the suggestion that astrocytes in vivo might communicate over long distances via intercellular $\mathrm{Ca}^{2+}$ waves (CornellBell et al. 1990). To date, there is little evidence that astrocytes in vivo show actively propagated intercellular $\mathrm{Ca}^{2+}$ waves that spread over long distances, but a variety of studies report widespread astrocyte $\mathrm{Ca}^{2+}$ responses in vivo in awake mice (Dombeck et al. 2007; Nimmerjahn et al. 2009; Ding et al. 2013) that may be mediated by the broad release of neuromodulators into large areas of brain tissue (Ding et al. 2013). This does not rule out the possibility that discrete clusters of astrocytes might be coupled through intercellular $\mathrm{Ca}^{2+}$ waves, and methods to monitor large cohorts (or all) astrocytes in vivo are needed. Moreover, one needs a computational framework to evaluate the probability distribution of time intervals between $\mathrm{Ca}^{2+}$ signals before we can determine whether signals in large populations of astrocytes are related or separate events. The mechanisms underlying intercellular $\mathrm{Ca}^{2+}$ waves have been studied extensively using cultured astroglia, and the overall consensus is that astroglia release ATP, which diffuses to neighboring cells to activate Gq-coupled puri- 
nergic receptors leading to increases in $\mathrm{Ca}^{2+}$ and consequent release of ATP to perpetuate the $\mathrm{Ca}^{2+}$ wave (Guthrie et al. 1999). Although the prevailing evidence suggests that gap junctionrelated proteins (pannexins/connexins) participate in the release of ATP from astroglia (Suadicani et al. 2004; Scemes and Spray 2012), alternate release pathways have also been described (Zhang et al. 2007; Kreft et al. 2009).

\section{The Nature of Astrocyte $\mathrm{Ca}^{2+}$ Signals Measured In Vivo in Nonanesthetized Adult Mice}

Technical developments from the Tank Laboratory (Princeton, NJ) have made it possible to image neurons and astrocytes in vivo during mouse behavior (Dombeck et al. 2007). Using these methods and two-photon microscopy on awake, head-fixed mice, these investigators discovered widespread astrocyte $\mathrm{Ca}^{2+}$ signals in layer two-thirds of the sensory cortex (Dombeck et al.2007). Across a population of experiments, $\sim 11 \%$ of astrocytes displayed $\mathrm{Ca}^{2+}$ signals that were strongly correlated with running behavior; the rest were partially or not correlated (Dombeck et al. 2007). Beautiful and detailed studies using similar methods revealed three types of $\mathrm{Ca}^{2+}$ signals within Bergmann glia of the cerebellum (Nimmerjahn et al. 2009). Two types of $\mathrm{Ca}^{2+}$ signals were ongoing within the cerebellum and were termed "sparkles" and "bursts," whereas a third form occurred in hundreds of Bergmann glia in a concerted manner during locomotor activity; these were termed "flares." Interestingly, the sparkles occurred mainly in processes and were reduced by tetrodotoxin (TTX) and glutamate receptor antagonists, implying they were driven at least in part by action potential dependent glutamate release (Nimmerjahn et al. 2009). Bursts occurred spontaneously in mice at rest and appeared as expanding waves that encompassed $\sim 55$ Bergmann glia (Nimmerjahn et al. 2009). These signals were not sensitive to TTX, but were abolished by PPADS, a nonspecific antagonist of ATP receptors, implying they were because of endogenous ATP (Nimmerjahn et al. 2009). Flares occurred during voluntary running and encompassed hundreds of Bergmann glia and were abolished by TTX and a glutamate receptor antagonist (Nimmerjahn et al. 2009). These studies elegantly show that a single type of astrocyte (i.e., the Bergmann glial cell) can display a variety of responses and mechanisms in vivo depending on what the mouse is doing. Moreover, during the course of these studies another fundamental observation was made. Anesthetics strongly disrupted $\mathrm{Ca}^{2+}$ signals within Bergmann glia (Nimmerjahn et al. 2009), recalling previous studies in the ferret visual cortex (Schummers et al. 2008). This insight has now been reproduced in studies of astrocytes in mouse cortex (Thrane et al. 2012). More recently, it has been shown that astrocyte $\mathrm{Ca}^{2+}$ responses in the mouse somatosensory cortex also encompass large populations of astrocytes and are driven by noradrenaline released from LC, which acts on $\alpha 1$ adrenoceptors on astrocytes (Ding et al. 2013). These investigators found that spontaneous $\mathrm{Ca}^{2+}$ signals were also driven by $\alpha 1$ adrenoceptors (Ding et al. 2013). Noradrenaline also engages Bergmann glia in the cerebellum and astrocytes in the visual cortex during vigilance in awake mice (Paukert et al. 2014).

The aforementioned in vivo studies represent a milestone because they provide a basis to explore and understand the physiological settings under which astrocytes respond to real-world experiences and behaviors that are engaged within the intact brain. Much more work is needed, but several general points are worth noting at this stage. First, anesthetics severely impair astrocyte $\mathrm{Ca}^{2+}$ signals and, hence, in vivo evaluations need to be performed on awake mice to faithfully study physiological $\mathrm{Ca}^{2+}$ signals. Second, a variety of $\mathrm{Ca}^{2+}$ signals can be observed in vivo, some are intrinsic, some driven by ATP, some by glutamate, and some by noradrenaline (Nimmerjahn et al. 2009; Ding et al. 2013; Paukert et al. 2014). What do these empirical observations mean? We suggest that when interpreting these studies it is important to avoid making strong generalizations based on observations on any one area of the brain, because the type of $\mathrm{Ca}^{2+}$ signal varies even within the cerebellum (Nimmerjahn et al. 2009), between brain areas, and also with the type of be- 
havioral response being evaluated. Indeed, it has been convincingly argued that astrocyte heterogeneity will be reflected as diverse types of astrocyte $\mathrm{Ca}^{2+}$ signals in vivo (Nimmerjahn et al. 2009) and in situ (Tong et al. 2012). In support of this concept, our recent data for the CA3 region show that astrocytes respond to bursts of action potentials with slow quite global $\mathrm{Ca}^{2+}$ signals (Haustein et al. 2014), which is different to astrocyte responses elsewhere in the hippocampus (Di Castro et al. 2011; Panatier et al. 2011). Moreover, the differences between the CA1 and CA3 regions may be explained by the structural differences between astrocytes processes and their proximity to postsynaptic densities. Hence, generalizations based on specific examples in any one area of the brain may be limited in any broadly meaningful sense. Third, it has been suggested that in vivo and in situ astrocyte studies fundamentally differ, because $\mathrm{Ca}^{2+}$ signals in vivo are quite widespread, whereas those in situ are more local (Ding et al. 2013). This is an interesting point that merits further consideration. It is noteworthy, however, that Bergmann glia and cortical astrocytes both display local (i.e., within processes) and widespread $\mathrm{Ca}^{2+}$ signals (Nimmerjahn et al. 2009). Moreover, it has already been shown that stimulation of the Schaffer collaterals results in widespread responses in at least 45 astrocytes in the hippocampus in situ, and that this number varies depending on the pathway being stimulated (Bowser and Khakh 2004). Furthermore, hippocampal astrocytes in situ also display local $\mathrm{Ca}^{2+}$ signals in processes (Nett et al. 2002; Di Castro et al. 2011; Panatier et al. 2011; Shigetomi et al. 2013a; Haustein et al. 2014). A conservative interpretation, therefore, suggests that there may not be an insurmountable biological schism between in vivo and in situ studies (Ding et al. 2013), but more work is certainly needed. Indeed, several decades of neuronal studies in vitro and in situ were necessary and portentous for hypothesis-driven experiments in vivo; there is no obvious reason to believe astrocytes will be different in this regard. Fourth, an early study on the adult cortex showed that astrocyte $\mathrm{Ca}^{2+}$ responses evoked by whisker stimulation were partly mediated by synaptic release of glu- tamate acting on astrocyte mGluR5 receptors (Wang et al. 2006), whereas a recent study concluded that glutamatergic signaling is insufficient to trigger astrocyte $\mathrm{Ca}^{2+}$ signaling and that mGluR5 receptors were not expressed in adult astrocytes (Sun et al. 2013). The causes of these differences are not clear, but clearly in vivo astrocyte $\mathrm{Ca}^{2+}$ signals are complex and diverse in nature. It is likely that a better understanding of astrocyte $\mathrm{Ca}^{2+}$ signals in vivo will allow us to design better experiments to explore astrocyte responses in situ in which exploration of biophysical and molecular mechanisms is more feasible. Moreover, the use of head-mounted wearable fluorescence microscopes (Ghosh et al. 2011) will permit the study of astrocytes in awake mice in deeper brain structures (Kuga et al. 2011; Sasaki et al. 2011). Hence, a nuanced assessment suggests that studies in vivo and in situ are both necessary to explore physiological settings and biophysical mechanisms. In particular, pharmacological mechanisms are difficult to assess in vivo because drugs have to be applied at concentrations that are often far in excess of their equilibrium dissociation constants. At such concentrations, cherished pharmacological concepts of specificity and selectively begin to fall apart, and yet it is these very concepts that make pharmacology useful as an experimental tool (Kenakin 2006). From this perspective, reduced preparations will continue to be necessary to explore mechanisms.

\section{APPROACHES TO ACTIVATE OR INACTIVATE ASTROCYTE $\mathrm{Ca}^{2+}$ SIGNALING}

To explore the causative functional role(s) of astrocyte $\mathrm{Ca}^{2+}$ signaling, it is essential to be able to specifically interfere with astrocyte $\mathrm{Ca}^{2+}$ signaling in complex brain tissue. This is relatively straightforward with neurons where one can activate or silence neuronal activity using electrophysiological or optogenetic methods. However, it is much more difficult with astrocytes given that evoked $\mathrm{Ca}^{2+}$ signaling arises almost exclusively from the activation of GPCRs that, as a family, are present on all cells. An additional complication is that, under physiological conditions, it is possible that micro- 
domains within an individual astrocyte respond to local neuronal activity without propagating the $\mathrm{Ca}^{2+}$ signal throughout the entire astrocyte (Di Castro et al. 2011; Panatier et al. 2011). Consequently, an astrocyte, which may envelop $\sim 100,000$ synapses, may be simultaneously responding to many different signals with responses affecting different neuronal events.

A large number of different approaches have been used to increase astrocyte $\mathrm{Ca}^{2+}$ in situ (Fiacco et al. 2009). Early studies applied GPCR agonists that resulted in $\mathrm{Ca}^{2+}$ release from the ER in the presence of agents that blocked neuronal activity and neurotransmitter release (Porter and McCarthy 1995; Nett et al. 2002) or simply stimulated neuronal activity and monitored astrocyte $\mathrm{Ca}^{2+}$ responses (Porter and McCarthy 1996; Bowser and Khakh 2004). These early studies showed that astrocytes express GPCRs linked to $\mathrm{Ca}^{2+}$ mobilization and that these GPCRs could be activated by neuronal activity. However, these findings provided little insight into the functional role of astrocyte $\mathrm{Ca}^{2+}$ signals. There is little doubt that certain GPCRs linked to $\mathrm{Ca}^{2+}$ mobilization are enriched in astrocytes relative to other cell types in brain (Agulhon et al. 2010). A number of investigators have taken advantage of this to selectively activate astrocyte $\mathrm{Ca}^{2+}$ signaling (reviewed in Santello and Volterra 2009; Halassa and Haydon 2010; Davila et al. 2013). An advantage of this approach is that endogenous GPCRs distributed appropriately over the surface of astrocytes are being used to generate $\mathrm{Ca}^{2+}$ signals. Thus, one may argue that astrocyte $\mathrm{Ca}^{2+}$ signals are likely to modulate neural activity in ways similar to that occurring under physiological conditions. A concern in using endogenous GPCR ligands to understand the functional consequences of astrocyte $\mathrm{Ca}^{2+}$ signals is that it is impossible to rule out the possibility that the endogenous ligand did not directly activate neuronal GPCRs. To circumvent this issue, a number of laboratories have used caged $\mathrm{Ca}^{2+}$ or caged $\mathrm{IP}_{3}$ to specifically increase $\mathrm{Ca}^{2+}$ in individual astrocytes (Fellin et al. 2004; Fiacco and McCarthy 2004; Wang et al. 2013). This is accomplished using patch pipettes to load individual astrocytes with caged $\mathrm{Ca}^{2+}$ or caged $\mathrm{IP}_{3}$. A large increase in astrocyte $\mathrm{Ca}^{2+}$ that generally initiates in the soma and propagates throughout the astrocyte is observed following uncaging by flash photolysis (Fiacco and McCarthy 2004). An advantage of using caged $\mathrm{IP}_{3}$ in relation to caged $\mathrm{Ca}^{2+}$ is that uncaging $\mathrm{IP}_{3}$ leads to $\mathrm{Ca}^{2+}$ release from the ER, which is likely to be more physiological than uncaging $\mathrm{Ca}^{2+}$ directly. Both of these approaches have been used to show that increases in astrocyte $\mathrm{Ca}^{2+}$ can lead to the release of gliotransmitters that affect neuronal activity (Fellin et al. 2004; Fiacco and McCarthy 2004). A problem associated with both of these approaches is that the $\mathrm{Ca}^{2+}$ increases often observed are very large (relative to those that occur under physiological conditions) and may trigger events that rarely, if ever, occur under normal settings (Fiacco et al. 2009). Indeed, the precise relationship between the amplitude of $\mathrm{Ca}^{2+}$ signals within astrocytes and their potential to engage downstream signaling has not been systematically studied. In light of this, it has been cogently suggested that astrocyte $\mathrm{Ca}^{2+}$ signals should not be interpreted in a simple on/off or "binary" manner in relation to their ability for downstream signaling (Shigetomi et al. 2008). Information could be encoded by the amplitude, location, duration, spatial spread, and frequency of astrocyte $\mathrm{Ca}^{2+}$ signals; these quantitative details need to be explored in physiologically relevant compartments of astrocytes (Rusakov et al. 2011).

One of us (McCarthy) took a pharmacogenetic approach to circumvent many of the caveats associated with the approaches described above. We engineered a transgenic mouse model that enabled us to inducibly express a Gq-GPCR (linked to $\mathrm{Ca}^{2+}$ mobilization) in astrocytes that is not normally expressed in brain, does not respond to known receptor ligands released in brain, and whose receptor ligand does not activate known GPCRs present in brain (Fiacco et al. 2007) . The Gq-GPCR (MrgA1) is normally expressed in a subpopulation of sensory neurons and is activated by the peptide FMRF (Dong et al. 2001). Using this transgenic mouse model, we showed that MrgAl was only expressed in astrocytes and that stimulation with FMRF led to a very similar temporal and spatial $\mathrm{Ca}^{2+}$ response as observed following stimulation of na- 
tive astrocyte Gq-GPCRs (Fiacco et al. 2007). In contrast to our findings following uncaging of $\mathrm{IP}_{3}$ in astrocytes (Fiacco and McCarthy 2004), increasing $\mathrm{Ca}^{2+}$ via the activation of MrgAl failed to affect basal or evoked synaptic transmission, or synaptic plasticity at the Schaffer collateral-CA1 synapse (Fiacco et al. 2007; Agulhon et al. 2010).

More recently, our laboratory (McCarthy) prepared a transgenic line that expresses an engineered Gq-GPCR known as hM3Dq driven by the GFAP promoter (Agulhon et al. 2013). $\mathrm{hM} 3 \mathrm{Dq}$ is part of the designer receptor exclusively activated by designer drugs (DREADD) GPCR family of engineered GPCRs (Armbruster et al. 2007). DREADD receptors fail to respond to endogenous GPCR ligands but do respond to the otherwise biological inert molecule, clozapine-N-oxide (CNO) (Nichols and Roth 2009). Chronic cranial window and genetically encoded $\mathrm{Ca}^{2+}$ sensors were used to monitor astrocyte responses to an ip injection of $\mathrm{CNO} . \mathrm{Ca}^{2+}$ responses similar to those elicited by endogenous ligands in brain slices were observed. Because CNO readily crosses the blood-brain barrier, for the first time, an analysis of the effect of activating astrocyte Gq-GPCR signaling on behavior could be performed. The activation of hM3Dq in $\mathrm{GFAP}^{+}$cells led to a striking phenotype that included increases in blood pressure, heart rate, saliva formation, a decrease in body temperature, and potentiation of sedation caused by a $\mathrm{GABA}_{\mathrm{A}}$ agonist (Agulhon et al. 2013). Surprisingly, a similar phenotype occurs in GFAP-hM3Dq mice that also lack $\mathrm{IP}_{3} \mathrm{R} 2 \mathrm{~s}$ in which astrocyte Gq-GPCR-dependent $\mathrm{Ca}^{2+}$ responses are abolished (Petravicz et al. 2008). This finding emphasizes the point that Gq-GPCRs regulate a wide variety of signaling cascades in addition to $\mathrm{Ca}^{2+}$ and that these are likely to be important in physiology and behavior. More recent unpublished studies from our laboratory (McCarthy) indicates that a cKO of $\mathrm{IP}_{3} \mathrm{R} 2$ fails to affect several routinely measures of behavior including tests for spatial plasticity (Morris water maze) suggesting that astrocyte $\mathrm{Ca}^{2+}$ responses are likely involved in the fine tuning of behavior opposed to being required for major behavioral events.
Recently, there have been spectacular advances in the use of optogenetics to explore neurons (Fenno et al. 2011). Some of these methods are now being applied to studies of astrocytes (Gourine et al. 2010; Sasaki et al. 2012), but more work is needed to determine whether these approaches trigger physiological $\mathrm{Ca}^{2+}$ signals within astrocytes or, like caged compounds, if they trigger signals that tend to be large. A new approach with increased temporal control of astrocyte $\mathrm{Ca}^{2+}$ involves LiGluR ( $\mathrm{Li}$ et al. 2012).

Not surprisingly, there are strengths and weaknesses associated with the use of pharmacogenetic and optogenetic methods to increase astrocyte $\mathrm{Ca}^{2+}$. The primary weakness of pharmacogenetic tools, such as DREADD receptors, is that it is difficult to limit the exposure time given that the ligand is typically administered systemically. This contrasts markedly with physiological responses that occur over seconds. A major strength of the pharmacogenetic approach is that the entire cascade of signaling molecules normally activated by GPCRs is activated, as opposed to a single downstream signal, such as $\mathrm{Ca}^{2+}$. Consequently, it is likely that the response is more physiological. The primary limitation of optogenetic excitation approaches is that astrocytes do not typically express voltagegated ion channels permeable to $\mathrm{Ca}^{2+}$, meaning that the method is reliant on the $\mathrm{Ca}^{2+}$ permeability of molecules like channelrhodopsin. It is unclear how the profile of $\mathrm{Ca}^{2+}$ entry through channelrhodopsin-like molecules is related to physiological astrocyte $\mathrm{Ca}^{2+}$ signals. Consequently, it seems likely that the temporal and spatial characteristics of astrocyte $\mathrm{Ca}^{2+}$ increases using this approach more closely resemble those obtained by directly uncaging $\mathrm{Ca}^{2+}$. The primary advantage of the optogenetic approach to increasing astrocyte $\mathrm{Ca}^{2+}$ is potentially higher temporal control. A consideration with both pharmacogenetic and optogenetic tools is that neither method enables one to control the level or spatial distribution of engineered receptors/ channels to sites normally activated in vivo. Hence, it is possible that both methods produce robust $\mathrm{Ca}^{2+}$ signals that fail to mimic physiological $\mathrm{Ca}^{2+}$ responses. 


\section{CONCLUDING REMARKS}

We have summarized how astrocyte $\mathrm{Ca}^{2+}$ signals are measured, their properties, their mechanisms, and some of their physiological roles. In the last few years, there has been considerable work on evaluating how astrocyte $\mathrm{Ca}^{2+}$ signals may, or may not, regulate neuronal activity. These topics, and the controversy that surrounds them, has already been reviewed in great detail (Agulhon et al. 2008, 2012; Halassa and Haydon 2010; Zorec et al. 2012). The topic is also covered in an accompanying article on gliotransmission. Rather than restating the arguments here, we make a few general points of relevance.

First, much more detailed work is needed to study the properties and biophysics of astrocyte $\mathrm{Ca}^{2+}$ signals in processes (Fig. 1). These data seem necessary to form specific hypotheses to explore distinct types of $\mathrm{Ca}^{2+}$ signal. It will be necessary in these studies to determine how closely astrocyte $\mathrm{Ca}^{2+}$ responses, and the consequences of these responses in acute brain slices, reflect those occurring in vivo. It is also important to note that in vivo imaging has so far only been performed on the superficial layers of the brain in awake mice; it is unlikely that findings from these studies will be reflective of the brain as a whole. The power of GECIs will be further increased as newer transcriptional units are identified that enable the expression of GECIs and knockdown constructs in defined subpopulations of astrocytes. Further, a better understanding of the molecules localizing GPCRs to specific subcellular sites will be critical for mimicking, with cell specificity, physiological activation of $\mathrm{Ca}^{2+}$ signaling. Second, it seems certain that astrocyte $\mathrm{Ca}^{2+}$ activity and downstream effects vary among different brain regions, as recently shown by one of us (Haustein et al. 2014). Consequently, it will be important to develop technology that enables monitoring of astrocyte and neuron activity in vivo in regions currently inaccessible using available GECIs and two-photon microscopy. The development of red-shifted GECIs and improved fluorescence endoscopy methods that enable imaging deep within tissues will undoubtedly lead to major advances in our understanding of astrocyte-neuronal interactions in vivo. Also, an expanded palette of indicators may permit the simultaneous imaging of astrocyte and neuronal signaling at high rates and with high cell coverage within entire microcircuits. If so, such developments have the potential to markedly advance our understanding of the correlative relationships between neuronal encoding and astrocyte $\mathrm{Ca}^{2+}$ signaling, an area that remains largely unexplored, although important progress has been made recently (Poskanzer and Yuste 2011). Third, much more work is needed to identify, genetically delete, and then explore the functions of distinct $\mathrm{Ca}^{2+}$ signals. IP3R2 conditional knockout mice are very useful to explore the predominant store-mediated $\mathrm{Ca}^{2+}$ signals in astrocytes and are likely to clarify the role of GPCR-mediated $\mathrm{Ca}^{2+}$ fluxes in physiology and behavior. Similar approaches are now needed for other astrocyte $\mathrm{Ca}^{2+}$ signals. Identification of the proteins that mediate astrocyte $\mathrm{Ca}^{2+}$ signals will markedly advance our understanding of the role of $\mathrm{Ca}^{2+}$ signaling in physiology. Fourth, methods to trigger physiologically relevant astrocyte signals are essential as each of the available methods have merits and limitations. These efforts would benefit greatly from detailed knowledge of $\mathrm{Ca}^{2+}$ responses to physiological stimuli. This will be essential for the field to evaluate the physiological relevance of the various $\mathrm{Ca}^{2+}$ responses that have been reported so far. Further, a detailed understanding of the temporal and spatial characteristics of astrocyte responses under physiological conditions will be critical for progress in this field. We believe that an ideal way to study physiological responses is to determine the settings under which astrocytes display $\mathrm{Ca}^{2+}$ signals in vivo in awake behaving mice during real-world experiences, such as sensory and motor stimuli. Such experiments are now underway (Dombeck et al. 2007; Nimmerjahn et al. 2009; Thrane et al. 2012; Ding et al. 2013) and will guide in situ mechanistic studies. It is notable that in vivo studies that use anesthesia may not reveal physiological responses because anesthetics themselves affect $\mathrm{Ca}^{2+}$ responses within astrocytes (Schummers et al. 2008; Nimmerjahn et al. 2009; Thrane et al. 2012). Fifth, we need rigorous analytical 
regimes, detection software and models of astrocyte $\mathrm{Ca}^{2+}$ signals in vivo so that relevant biological questions can be framed precisely. Sixth, we need to develop testable concepts and experimental frameworks to explore the roles of astrocytes in model microcircuits that are relevant to behavioral endpoints in whole mice.

Once we can reliably measure, mimic, and block specific astrocyte $\mathrm{Ca}^{2+}$ signals with high temporal and spatial precision, then the field will be in a strong position to continue to explore the correlative and causative roles that $\mathrm{Ca}^{2+}$ signals may have for the functions of synapses, neurons, and circuits. These roles may affect synaptic transmission, vascular tone, synapse formation, synapse removal, plasticity, and inflammation. They may also include slower passive neuromodulatory functions driven by basal $\mathrm{Ca}^{2+}$ levels as recently suggested (Khakh and North 2012; Tong et al. 2012). Perhaps, equally likely is the possibility that $\mathrm{Ca}^{2+}$ signals may regulate the supportive and trophic functions of astrocytes, at least in part, through regulation of gene expression. The next decade of research in this area will continue to clarify the role of astrocytes in physiology, behavior, and neurological/psychiatric diseases as the availability of new tools enables investigators to selectively monitor, mimic, and block astrocyte $\mathrm{Ca}^{2+}$ signaling cascades in situ and in vivo. The next few years look very exciting for astrocyte biology.

\section{ACKNOWLEDGMENTS}

We regret that we could not cite many worthy papers because of space constraints. B.S.K. and K.D.M. are grateful to current and past members of our laboratories for discussions. The Khakh laboratory is supported by the $\mathrm{Na}$ tional Institutes of Health (NIH) (NS060677, MH104069, MH099559) and the Cure Huntington's Disease Initiative (CHDI) Foundation. The McCarthy laboratory is supported by the NIH (NS020212, MH099564, NS081589, EY021190).

\section{REFERENCES}

Agulhon C, Petravicz J, McMullen AB, Sweger EJ, Minton SK, Taves SR, Casper KB, Fiacco TA, McCarthy KD. 2008.
What is the role of astrocyte calcium in neurophysiology? Neuron 59: 932-946.

Agulhon C, Fiacco TA, McCarthy KD. 2010. Hippocampal short- and long-term plasticity are not modulated by astrocyte $\mathrm{Ca}^{2+}$ signaling. Science 327: 1250-1254.

Agulhon C, Sun MY, Murphy T, Myers T, Lauderdale K, Fiacco TA. 2012. Calcium signaling and gliotransmission in normal vs. reactive astrocytes. Front Pharmacol 3: 139.

Agulhon C, Boyt KM, Xie AX, Friocourt F, Roth BL, McCarthy KD. 2013. Modulation of the autonomic nervous system and behaviour by acute glial cell Gq protein-coupled receptor activation in vivo. J Physiol 591: 55995609.

Akerboom J, Chen TW, Wardill TJ, Tian L, Marvin JS, Mutlu S, Calderón NC, Esposti F, Borghuis BG, Sun XR, et al. 2012. Optimization of a GCaMP calcium indicator for neural activity imaging. J Neurosci 32: 2601-2612.

Armbruster BN, Li X, Pausch MH, Herlitze S, Roth BL. 2007. Evolving the lock to fit the key to create a family of $\mathrm{G}$ protein-coupled receptors potently activated by an inert ligand. Proc Natl Acad Sci 104: 5163-5168.

Aston-Jones G, Cohen JD. 2005. Adaptive gain and the role of the locus coeruleus-norepinephrine system in optimal performance. J Comp Neurol 493: 99-110.

Atkin SD, Patel S, Kocharyan A, Holtzclaw LA, Weerth SH, Schram V, Pickel J, Russell JT. 2009. Transgenic mice expressing a cameleon fluorescent $\mathrm{Ca}^{2+}$ indicator in astrocytes and Schwann cells allow study of glial cell $\mathrm{Ca}^{2+}$ signals in situ and in vivo. J Neursci Methods 181: 212-226.

Benediktsson AM, Schachtele SJ, Green SH, Dailey ME. 2005. Ballistic labeling and dynamic imaging of astrocytes in organotypic hippocampal slice cultures. J Neurosci Methods 141: 41-53.

Berridge MJ, Bootman MD, Roderick HL. 2003. Calcium signalling: Dynamics, homeostasis and remodelling. Nat Rev Mol Cell Biol 4: 517-529.

Bischofberger J, Engel D, Li L, Geiger JR, Jonas P. 2006. Patch-clamp recording from mossy fiber terminals in hippocampal slices. Nat Protoc 1: 2075-2081.

Bowser DN, Khakh BS. 2004. ATP excites interneurons and astrocytes to increase synaptic inhibition in neuronal networks. J Neurosci 24: 8606-8620.

Carmignoto G, Haydon PG. 2012. Astrocyte calcium signaling and epilepsy. Glia 60: 1227-1233.

Charles AC, Merrill JE, Dirksen ER, Sanderson MJ. 1991. Intercellular signaling in glial cells: Calcium waves and oscillations in response to mechanical stimulation and glutamate. Neuron 6: 983-992.

Chen TW, Wardill TJ, Sun Y, Pulver SR, Renninger SL, Baohan A, Schreiter ER, Kerr RA, Orger MB, Jayaraman V, et al. 2013. Ultrasensitive fluorescent proteins for imaging neuronal activity. Nature 499: 295-300.

Clapham DE. 2007. Calcium signaling. Cell 131: 10471058.

Cornell-Bell AH, Finkbeiner SM, Cooper MS, Smith SJ. 1990. Glutamate induces calcium waves in cultured astrocytes: Long-range glial signaling. Science 247: 470473.

Dani JW, Chernjavsky A, Smith SJ. 1992. Neuronal activity triggers calcium waves in hippocampal astrocyte networks. Neuron 8: 429-440. 
Davila D, Thibault K, Fiacco TA, Agulhon C. 2013. Recent molecular approaches to understanding astrocyte function in vivo. Front Cell Neurosci 7: 272.

Di Castro MA, Chuquet J, Liaudet N, Bhaukaurally K, Santello M, Bouvier D, Tiret P, Volterra A. 2011. Local Ca ${ }^{2+}$ detection and modulation of synaptic release by astrocytes. Nat Neurosci 10: 1276-1284.

Ding F, O’Donnell J, Thrane AS, Zeppenfeld D, Kang H, Xie L, Wang F, Nedergaard M. 2013. $\alpha 1$-Adrenergic receptors mediate coordinated $\mathrm{Ca}^{2+}$ signaling of cortical astrocytes in awake, behaving mice. Cell Calcium 54: 387-394.

Dombeck DA, Khabbaz AN, Collman F, Adelman TL, Tank DW. 2007. Imaging large-scale neural activity with cellular resolution in awake, mobile mice. Neuron 56: 43-57.

Dong X, Han S, Zylka MJ, Simon MI, Anderson DJ. 2001. A diverse family of GPCRs expressed in specific subsets of nociceptive sensory neurons. Cell 106: 619-632.

Fatatis A, Russell JT. 1992. Spontaneous changes in intracellular calcium concentration in type I astrocytes from rat cerebral cortex in primary culture. Glia 5: 95-104.

Fellin T, Pascual O, Gobbo S, Pozzan T, Haydon PG, Carmignoto G. 2004. Neuronal synchrony mediated by astrocytic glutamate through activation of extrasynaptic NMDA receptors. Neuron 43: 729-743.

Fenno L, Yizhar O, Deisseroth K. 2011. The development and application of optogenetics. Annu Rev Neurosci 34: 389-412.

Fiacco TA, McCarthy KD. 2004. Intracellular astrocyte calcium waves in situ increase the frequency of spontaneous AMPA receptor currents in CA1 pyramidal neurons. $J$ Neurosci 24: 722-732.

Fiacco TA, Agulhon C, Taves SR, Petravicz J, Casper KB, Dong X, Chen J, McCarthy KD. 2007. Selective stimulation of astrocyte calcium in situ does not affect neuronal excitatory synaptic activity. Neuron 54: 611-626.

Fiacco TA, Agulhon C, McCarthy KD. 2009. Sorting out astrocyte physiology from pharmacology. Annu Rev Pharmacol Toxicol 49: 151-174.

Ghosh KK, Burns LD, Cocker ED, Nimmerjahn A, Ziv Y, Gamal AE, Schnitzer MJ. 2011. Miniaturized integration of a fluorescence microscope. Nat Methods 8: 871-878.

Gourine AV, Kasymov V, Marina N, Tang F, Figueiredo MF, Lane S, Teschemacher AG, Spyer KM, Deisseroth K, Kasparov S. 2010. Astrocytes control breathing through $\mathrm{pH}$ dependent release of ATP. Science 329: 571-575.

Guthrie PB, Knappenberger J, Segal M, Bennett MVL, Charles AC, Kater SB. 1999. ATP released from astrocytes mediates glial calcium waves. 19: 520-528.

Halassa MM, Haydon PG. 2010. Integrated brain circuits: Astrocytic networks modulate neuronal activity and behavior. Annu Rev Physiol 72: 335-355.

Haustein MD, Kracun S, Lu X-H, Shih T, Jackson-Weaver O, Tong X, Xu J, Yang XW, O’Dell T, J., Marvin JS, et al. 2014. Conditions and constraints for astrocyte calcium signaling in the hippocampal mossy fiber pathway. Neuron 82: 413-429.

Hires SA, Tian L, Looger LL. 2008. Reporting neural activity with genetically encoded calcium indicators. Brain Cell Biol 36: 69-86.

Kenakin TP. 2006. A pharmacology primer: Theory, applications and methods. Academic, London.
Khakh BS, North RA. 2012. Neuromodulation by extracellular ATP and P2X receptors in the CNS. Neuron 76: 5169.

Kreft M, Potokar M, Stenovec M, Pangrsic T, Zorec R. 2009. Regulated exocytosis and vesicle trafficking in astrocytes. Ann NY Acad Sci 1152: 30-42.

Kuga N, Sasaki T, Takahara Y, Matsuki N, Ikegaya Y. 2011. Large-scale calcium waves traveling through astrocytic networks in vivo. J Neurosci 31: 2607-2614.

Li D, Hérault K, Isacoff EY, Oheim M, Ropert N. 2012. Optogenetic activation of LiGluR-expressing astrocytes evokes anion channel-mediated glutamate release. J Physiol 590: 855-873.

Li D, Agulhon C, Schmidt E, Oheim M, Ropert N. 2013. New tools for investigating astrocyte-to-neuron communication. Front Cell Neurosci 7: 193.

Malarkey EB, Ni Y, Parpura V. 2008. $\mathrm{Ca}^{2+}$ entry through TRPC1 channels contributes to intracellular $\mathrm{Ca}^{2+} \mathrm{dy}-$ namics and consequent glutamate release from rat astrocytes. Glia 56: 821-835.

Melom JE, Littleton JT. 2013. Mutation of a NCKX eliminates glial microdomain calcium oscillations and enhances seizure susceptibility. J Neurosci 33: 1169-1178.

Nedergaard M, Rodríguez JJ, Verkhratsky A. 2010. Glial calcium and diseases of the nervous system. Cell Calcium 47: $140-149$.

Neher E. 2000. Some quantitative aspects of calcium fluorimtery. In Imaging neurons: A laboratory manual (ed. Yuste R, Lanni F, Konnerth A), Cold Spring Harbor Laboratory Press, Cold Spring Harbor, NY.

Nett WJ, Oloff SH, McCarthy KD. 2002. Hippocampal astrocytes in situ exhibit calcium oscillations that occur independent of neuronal activity. J Neurophysiol 87: $528-537$.

Nichols CD, Roth BL. 2009. Engineered G-protein coupled receptors are powerful tools to investigate biological processes and behaviors. Front Mol Neurosci 2: 16.

Nimmerjahn A, Kirchhoff F, Kerr JN, Helmchen F. 2004. Sulforhodamine 101 as a specific marker of astroglia in the neocortex in vivo. Nat Methods 1:31-37.

Nimmerjahn A, Mukamel EA, Schnitzer MJ. 2009. Motor behavior activates Bergmann glial networks. Neuron 62: 400-412.

O’Donnell J, Zeppenfeld D, McConnell E, Pena S, Nedergaard M. 2012. Norepinephrine: A neuromodulator that boosts the function of multiple cell types to optimize CNS performance. Neurochem Res 37: 2496-2512.

Palygin O, Lalo U, Verkhratsky A, Pankratov Y. 2010. Ionotropic NMDA and $\mathrm{P} 2 \mathrm{X} 1 / 5$ receptors mediate synaptically induced $\mathrm{Ca}^{2+}$ signalling in cortical astrocytes. Cell Calcium 48: 225-231.

Panatier A, Vallée J, Haber M, Murai KK, Lacaille JC, Robitaille R. 2011. Astrocytes are endogenous regulators of basal transmission at central synapses. Cell 146: 785798.

Pankratov Y, Lalo U. 2014. Calcium permeability of ligandgated $\mathrm{Ca}^{2+}$ channels. Eur J Pharmacol 739: 60-73.

Paukert M, Agarwal A, Jaepyeong C, Doze VA, Kang JU, Bergles DW. 2014. Norepinephrine controls astroglial responsiveness to local circuit activity. Neuron 82: 1263 1270. 
B.S. Khakh and K.D. McCarthy

Petravicz J, Fiacco TA, McCarthy KD. 2008. Loss of IP3 receptor-dependent $\mathrm{Ca}^{2+}$ increases in hippocampal astrocytes does not affect baseline CA1 pyramidal neuron synaptic activity. J Neurosci 28: 4967-4973.

Porter JT, McCarthy KD. 1995. GFAP-positive hippocampal astrocytes in situ respond to glutamatergic neuroligands with increases in $\left[\mathrm{Ca}^{2+}\right]_{\mathrm{i}}$. Glia 13: 101-112.

Porter JT, McCarthy KD. 1996. Hippocampal astrocytes in situ respond to glutamate released from synaptic terminals. J Neurosci 16: 5073-5081.

Poskanzer KE, Yuste R. 2011. Astrocytic regulation of cortical UP states. Proc Natl Acad Sci 108: 18453-18458.

Rand MN, Leinders-Zufall T, Agulian S, Kocsis JD. 1994. Calcium signals in neurons. Nature 371: 291-292.

Reeves A, Shigetomi E, Khakh BS. 2011. Bulk loading of calcium indicator dyes to study astrocyte physiology: Key limitations and improvements using morphological maps. J Neurosci 31: 9353-9358.

Rusakov DA, Zheng K, Henneberger C. 2011. Astrocytes as regulators of synaptic function: A quest for the $\mathrm{Ca}^{2+}$ master key. Neuroscientist 17: 513-523.

Russell JT. 2011. Imaging calcium signals in vivo: A powerful tool in physiology and pharmacology. Br J Pharmacol 163: $1605-1625$

Santello M, Volterra A. 2009. Synaptic modulation by astrocytes via $\mathrm{Ca}^{2+}$-dependent glutamate release. Neuroscience 158: $253-259$.

Sasaki T, Kuga N, Namiki S, Matsuki N, Ikegaya Y. 2011. Locally synchronized astrocytes. Cereb Cortex 21: 1889 1900.

Sasaki T, Beppu K, Tanaka KF, Fukazawa Y, Shigemoto R, Matsui K. 2012. Application of an optogenetic byway for perturbing neuronal activity via glial photostimulation. Proc Natl Acad Sci 109: 20720-20725.

Scanziani M, Häusser M. 2009. Electrophysiology in the age of light. Nature 461: 930-939.

Scemes E, Spray DC. 2012. Extracellular $\mathrm{K}^{+}$and astrocyte signaling via connexin and pannexin channels. Neurochem Res 37: 2310-2316.

Schummers J, Yu H, Sur M. 2008. Tuned responses of astrocytes and their influence on hemodynamic signals in the visual cortex. Science 320: 1638-1643.

Shao Y, McCarthy KD. 1993. Quantitative relationship between alpha 1-adrenergic receptor density and the receptor-mediated calcium response in individual astroglial cells. Mol Pharmacol 44: 247-254.

Shigetomi E, Bowser DN, Sofroniew MV, Khakh BS. 2008. Two forms of astrocyte calcium excitability have distinct effects on NMDA receptor-mediated slow inward currents in pyramidal neurons. J Neurosci 28: 66596663.

Shigetomi E, Kracun S, Khakh BS. 2010a. Monitoring astrocyte calcium microdomains with improved membrane targeted GCaMP reporters. Neuron Glia Biol 6: 183-191.

Shigetomi E, Kracun S, Sofroniew MV, Khakh BS. 2010b. A genetically targeted optical sensor to monitor calcium signals in astrocyte processes. Nat Neurosci 13: 759-766.

Shigetomi E, Tong X, Kwan KY, Corey DP, Khakh BS. 2011. TRPA1 channels regulate astrocyte resting calcium and inhibitory synapse efficacy through GAT-3. Nat Neurosci 15: $70-80$.
Shigetomi E, Bushong EA, Haustein MD, Tong X, JacksonWeaver O, Kracun S, Xu J, Sofroniew MV, Ellisman MH, Khakh BS. 2013a. Imaging calcium microdomains within entire astrocyte territories and endfeet with GCaMPs expressed using adeno-associated viruses. J Gen Physiol 141: 633-647.

Shigetomi E, Jackson-Weaver O, Huckstepp RT, O’Dell TJ, Khakh BS. 2013b. TRPA1 channels are regulators of astrocyte basal calcium levels and long-term potentiation via constitutive D-serine release. J Neurosci 33: 10143 10153.

Smith SJ. 1992. Do astrocytes process neural information? Prog Brain Res 94: 119-136.

Smith S. 1994. Neural signalling. Neuromodulatory astrocytes. Curr Biol 4: 807-810.

Stuart GJ, Dodt HU, Sakmann B. 1993. Patch-clamp recordings from the soma and dendrites of neurons in brain slices using infrared video microscopy. Pflugers Arch 423: 511-518.

Suadicani SO, Flores CE, Urban-Maldonado M, Beelitz M, Scemes E. 2004. Gap junction channels coordinate the propagation of intercellular $\mathrm{Ca}^{2+}$ signals generated by P2Y receptor activation. Glia 48: 217-229.

Sun W, McConnell E, Pare JF, Xu Q, Chen M, Peng W, Lovatt D, Han X, Smith Y, Nedergaard M. 2013. Glutamatedependent neuroglial calcium signaling differs between young and adult brain. Science 339: 197-200.

Thrane AS, Rangroo Thrane V, Zeppenfeld D, Lou N, Xu Q, Nagelhus EA, Nedergaard M. 2012. General anesthesia selectively disrupts astrocyte calcium signaling in the awake mouse cortex. Proc Natl Acad Sci 109: 18974 18979.

Tian L, Hires SA, Mao T, Huber D, Chiappe ME, Chalasani SH, Petreanu L, Akerboom J, McKinney SA, Schreiter ER, et al. 2009. Imaging neural activity in worms, flies and mice with improved GCaMP calcium indicators. Nat Methods 6: 875-881.

Tong X, Shigetomi E, Looger LL, Khakh BS. 2012. Genetically encoded calcium indicators and astrocyte calcium microdomains. Neuroscientist 19: 274-291.

Tsien RY. 1988. Fluorescence measurement and photochemical manipulation of cytosolic free calcium. Trends Neurosci 11: 419-424.

Tsien RY. 1989. Fluorescent probes of cell signaling. Annu Rev Neurosci 12: 227-253.

Wang X, Lou N, Xu Q, Tian GF, Peng WG, Han X, Kang J, Takano T, Nedergaard M. 2006. Astrocytic $\mathrm{Ca}^{2+}$ signaling evoked by sensory stimulation in vivo. Nat Neurosci 9: $816-823$.

Wang F, Smith NA, Xu Q, Goldman S, Peng W, Huang JH, Takano T, Nedergaard M. 2013. Photolysis of caged $\mathrm{Ca}^{2+}$ but not receptor-mediated $\mathrm{Ca}^{2+}$ signaling triggers astrocytic glutamate release. J Neurosci 33: $17404-$ 17412.

Yuste R, Katz LC. 1991. Control of postsynaptic $\mathrm{Ca}^{2+}$ influx in developing neocortex by excitatory and inhibitory neurotransmitters. Neuron 6: 333-344.

Zariwala HA, Borghuis BG, Hoogland TM, Madisen L, Tian L, De Zeeuw CI, Zeng H, Looger LL, Svoboda K, Chen TW. 2012. ACre-dependent GCaMP3 reporter mouse for neuronal imaging in vivo. J Neurosci 32: 2131-2141. 
Zhang Z, Chen G, Zhou W, Song A, Xu T, Luo Q, Wang W, Gu XS, Duan S. 2007. Regulated ATP release from astrocytes through lysosome exocytosis. Nat Cell Biol 9: 945953.

Zlatkine P, Mehul B, Magee AI. 1997. Retargeting of cytosolic proteins to the plasma membrane by the Lck protein tyrosine kinase dual acylation motif. J Cell Sci 110: 673679.

Zorec R, Araque A, Carmignoto G, Haydon PG, Verkhratsky A, Parpura V. 2012. Astroglial excitability and gliotransmission: An appraisal of $\mathrm{Ca}^{2+}$ as a signalling route. ASN Neuro 4: e00080. 


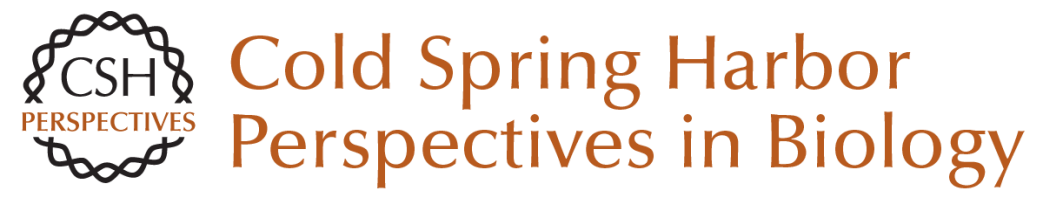

\title{
Astrocyte Calcium Signaling: From Observations to Functions and the Challenges Therein
}

\author{
Baljit S. Khakh and Ken D. McCarthy
}

Cold Spring Harb Perspect Biol 2015; doi: 10.1101/cshperspect.a020404 originally published online January 20, 2015

\section{Subject Collection Glia}

The Nodes of Ranvier: Molecular Assembly and Maintenance Matthew N. Rasband and Elior Peles

Microglia in Health and Disease Richard M. Ransohoff and Joseph El Khoury

The Astrocyte: Powerhouse and Recycling Center Bruno Weber and L. Felipe Barros

Microglia Function in Central Nervous System Development and Plasticity Dorothy P. Schafer and Beth Stevens

Transcriptional and Epigenetic Regulation of Oligodendrocyte Development and Myelination in the Central Nervous System Ben Emery and Q. Richard Lu

Origin of Microglia: Current Concepts and Past Controversies

Florent Ginhoux and Marco Prinz

Glia Disease and Repair--Remyelination Robin J.M. Franklin and Steven A. Goldman

Astrocytes in Neurodegenerative Disease Hemali Phatnani and Tom Maniatis
Oligodendrocyte Development and Plasticity Dwight E. Bergles and William D. Richardson

Oligodendrocytes: Myelination and Axonal

Support Mikael Simons and Klaus-Armin Nave

Drosophila Central Nervous System Glia Marc R. Freeman

Perisynaptic Schwann Cells at the Neuromuscular Synapse: Adaptable, Multitasking Glial Cells Chien-Ping Ko and Richard Robitaille

Astrocytes Control Synapse Formation, Function, and Elimination Won-Suk Chung, Nicola J. Allen and Cagla Eroglu

Schwann Cell Myelination James L. Salzer

Schwann Cells: Development and Role in Nerve Repair Kristján R. Jessen, Rhona Mirsky and Alison C. Lloyd

Perineurial Glia

Sarah Kucenas

For additional articles in this collection, see http://cshperspectives.cshlp.org/cgi/collection/

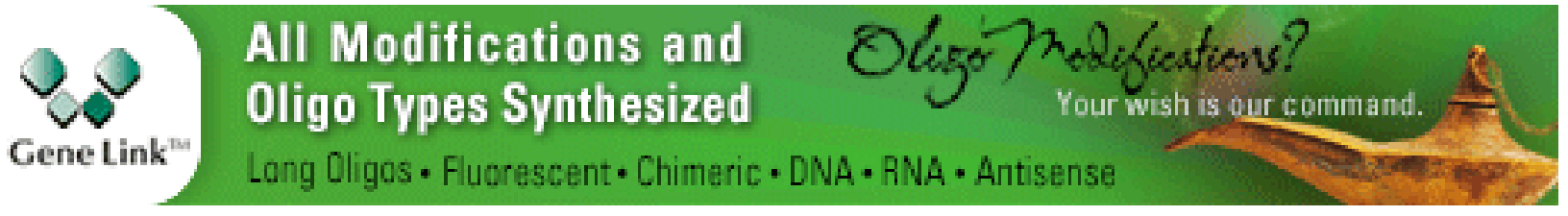

